\title{
Predominance and geo-mapping of avian influenza H5N1 in poultry sectors in Egypt
}

\author{
Abdelsatar Arafa, ${ }^{1,2}$ Ihab El-Masry, ${ }^{1}$ Shereen Khoulosy, ${ }^{2}$ Mohammed K. Hassan, ${ }^{2}$ \\ Moussa Soliman, ${ }^{3}$ Olubunmi G. Fasanmi, ${ }^{4,5}$ Folorunso O. Fasina, ${ }^{6,7}$ Gwenaelle Dauphin, ${ }^{8}$ \\ Juan Lubroth, ${ }^{8}$ Yilma M. Jobre ${ }^{7}$ \\ ${ }^{1}$ Emergency Center of Transboundary Animal Diseases, Food and Agriculture Organization \\ of the United Nations, Giza; ${ }^{2}$ National Laboratory for Veterinary Quality Control on Poultry \\ Production, Animal Health Research Institute, Giza; ${ }^{3}$ General Organization of Veterinary \\ Services, Giza, Egypt; ${ }^{4}$ Department of Production Animal Studies, University of Pretoria, \\ Pretoria, South Africa; ${ }^{5}$ Department of Animal Health, Federal College of Animal Health \\ and Production Technology, Ibadan, Nigeria; ${ }^{6}$ Department of Veterinary Tropical Diseases, \\ University of Pretoria, Pretoria, South Africa; ${ }^{7}$ Emergency Center of Transboundary Animal \\ Diseases, Food and Agriculture Organization of the United Nations, Gigiri, Kenya; ${ }^{8}$ Food \\ and Agriculture Organization of the United Nations, Rome, Italy
}

\begin{abstract}
Highly pathogenic avian influenza (HPAI) virus of the H5N1 subtype has been enzootic in the Egyptian poultry with significant human infections since 2008. This work evaluates the epidemiological and virological information from February 2006 to May 2015 in spatial and
\end{abstract}

\footnotetext{
Correspondence: Folorunso Oludayo Fasina, Department of Veterinary Tropical Diseases, Faculty of Veterinary Science, University of Pretoria, Onderstepoort, Soutpan Rd, 0110 Pretoria, South Africa.

Tel: +27.849581925 - Fax $+27-125298369$.

E-mail: daydupe2003@yahoo.co.uk

Key words: HPAI H5N1; Poultry; Epidemiology; Virus evolution; Egypt.

Acknowledgements: this work was supported by the United States Agency for International Development (USAID) (grant number AID-263-I0-11-00001, Mod.\#3) in the framework of OSR0/EGY/501/USA, through projects jointly implemented by the FAO, General Organization for Veterinary Services and NLQP. The authors express their sincere gratitude to USAID for its continued support in addressing the endemic HPAI situation in Egypt.

Conflict of interest: the authors declare no potential conflict of interest.

Received for publication: 5 June 2016.

Revision received: 29 August 2016.

Accepted for publication: 9 September 2016.

(C) Copyright A. Arafa et al., 2016

Licensee PAGEPress, Italy

Geospatial Health 2016; 11:492

doi:10.4081/gh.2016.492

This article is distributed under the terms of the Creative Commons Attribution Noncommercial License (CC BY-NC 4.0) which permits any noncommercial use, distribution, and reproduction in any medium, provided the original author(s) and source are credited.
}

temporal terms. Only data with confirmed HPAI H5N1 sub-type were collected, and matched with the epidemiological data from various spatially and temporally-dispersed surveillances implemented between 2006 and 2015. Spatio-temporal analysis was conducted on a total of 3338 confirmed H5N1 HPAI poultry disease outbreaks and outputs described based on transmission patterns, poultry species, production types affected, trade, geographic and temporal distributions in Egypt. The H5N1 virus persists in the Egyptian poultry displaying a seasonal pattern with peak prevalence between January and March. There was no specific geographic pattern, but chickens and ducks were more affected. However, relatively higher disease incidences were recorded in the Nile Delta. Phylogenetic studies of the haemagglutinin gene sequences of $\mathrm{H} 5 \mathrm{~N} 1$ viruses indicated that multiple clusters circulated between 2006 and 2015, with significant deviations in circulation. Epidemiological dynamics of HPAI has changed with the origins of majority of outbreaks shifted to household poultry. The persistence of HPAI H5N1 in poultry with recurrent and sporadic infections in humans can influence virus evolution spatio-temporally. Household poultry plays significant roles in the $\mathrm{H} 5 \mathrm{~N} 1$ virus transmission to poultry and humans, but the role of commercial poultry needs further clarifications. While poultry trading supports the persistence and transmission of $\mathrm{H} 5 \mathrm{~N} 1$, the role of individual species may warrant further investigation. Surveillance activities, applying a multi-sectoral approach, are recommended.

\section{Introduction}

A total of $854 \mathrm{H} 5 \mathrm{~N} 1$ human influenza cases have been reported worldwide as of 19 July 2016 with 450 deaths, giving a case fatality rate (CFR) of $\approx 53 \%$ (WHO, 2016). Since 2003 , a total of 16 countries have confirmed H5N1 cases in human, with the largest number of infected humans recorded in Egypt (350), followed by Indonesia (199) and Vietnam (127) according the the World Health Organization (WHO, 2016). Egypt reported 354 confirmed human cases in total, with 117 deaths (CFR of 33\%). Between November 2014 and 30 April 2015, a 
total of 165 human cases were reported and 48 deaths were confirmed by the national health authorities, the highest number of human cases ever reported by any country over a similar period (WHO-EMRO, 2015). In the first 24 weeks of 2015 alone, Egypt registered more than 33 times the total number of human cases reported in 2013 and 12 times the numbers of deaths. Most of the human cases have been associated with household poultry production, while very low numbers have been associated with either the commercial poultry production sector or the live bird markets (LBMs). The H5N1 viruses isolated from household duck, chicken and human cases from Egypt were clustered into a distinct genetic group designated as clade 2.2.1 (Arafa et al., 2015). Besides, the majority of the viruses derived from vaccinated poultry in commercial farms belonged to clade 2.2.1.1 (FA0, 2011; WHO/OIE/FAO, 2012; OIE, 2013) and in recent times, a novel cluster of clade 2.2.1.2 with probable human health impact have emerged (Arafa et al., 2015).

Egypt has a considerably large poultry production sector, where the registered and unregistered commercial farms are estimated to be approximately 27,000 . The industry produces a range of products including broilers, layers, breeders, grandparents, local (Baladi) chickens, different duck breeds (Peking, Muscovy, Mule and Sudani), geese, turkeys, ostriches and quails (FA0, 2013). The majority (approximately $81 \%$ of the broilers, $64 \%$ of the layers, $79 \%$ of the ducks and $39 \%$ of the turkey farms) are from Lower Egypt, while Middle Egypt (Cairo and Giza) represents the second largest (13, 29, 14 and 49\%, respectively). The remainder of commercial farms are found in Upper Egypt (Jones, 2008).The backyard breeding and meat production (Sector four) often called the household poultry plays a key role the H5N1 dynamic in poultry in Egypt and have been shown to play significant roles in human and poultry infections (Abdel-Moneim et al., 2009; Abdelwhab and Hafez, 2011; El-Masry et al., 2015). This sector is characterized by randomly dispersed, small-sized, individually-owned household flocks that usually are raised as mixed bird species of different ages in Egypt (Fasina et al., 2016). Poultry movements in Egypt involve large numbers of small holders and traders moving birds to and from the live-bird markets. Poultry products are mainly sold directly or to the traders in the markets. An extensively description of the four sectors of the global poultry industry has been made by Upton (2007). A careful analysis of the spatio-temporal patterns of H5N1 clusters in Egypt matched with genetic data can provide the basis for identifying the high-risk areas in order to explore sources and transmission patterns of the virus. The development in the field of spatial epidemiology, particularly spatial statistics and spatial software, has created opportunities to examine the in-depth pattern of disease over space and time. Geo-mapping is a visual representation of the geographical location(s) of events and activities in layers on top of an interactive map or satellite imagery.

The aim of the present study is to gain understanding of the geographic source of influenza virus infections and seasonality of the epidemics using epidemiological and virological data from past outbreaks as this will aid the understanding of the evolutionary dynamics of endemic H5N1 viruses in Egypt.

\section{Materials and Methods}

\section{Sampling and epidemiological data collection}

From February 2006 until May 2015, more than 2 million birds have been sampled as part of the national avian influenza (AI) surveillance programme. Based on the surveillance plans, oro-pharyngeal and/or cloacal swabs were collected from apparently healthy or clinically ill birds. Epidemiological data (including date of sampling, bird species, production type and location) used in this study were collected and matched with the biological samples. All field samples were collected in phosphate-buffered saline with a single antibiotic of type penicillin, streptomycin, gentamycin, or combinations thereof, and then delivered on ice $\left(\approx 4^{\circ} \mathrm{C}\right)$ to the central National Laboratory for Veterinary Quality Control of Poultry Production (NLQP), Dokki, Giza, Egypt or one of its satellite laboratories. When samples were collected, spatio-temporal epidemiological data were collected simultaneously and aligned with each sample, or group of samples.

\section{Genotyping and phylogenetic analysis}

The samples were tested for the AIV H5 subtype using real-time reverse transcriptase-polymerase chain reaction (RT-PCR) on the extracted RNAs and specific primers for $\mathrm{M}$ and $\mathrm{H} 5$ genes according to Spackman et al. (2002) and Slomka et al. (2007). From the collected samples, a total of 3338 were confirmed positive for H5N1 subtype. Genotyping and phylogenetic analysis were done using a number of selected but representative sequences $(n=164)$. The Neighbor-Joining consensus for unrooted phylogenetic tree of the haemagglutinin (HA) gene sequences of Egyptian H5N1 viruses was constructed using Geneious software version R8 (Biomatters, Auckland, New Zealand).

\section{Spatial analysis}

Spatio-temporal data and collected parameters were prepared in a Microsoft Excel spreadsheet, filtered and exported into the EPIPOI software (http://www.epipoi.info/) (Alonso and McCormick, 2012). Temporal (time series) data file was prepared by inputting the organized annual and finer resolution monthly counts of tested and confirmed samples into an Excel spreadsheet. Each column was dedicated to a series of observations and no data gap was allowed in the time series. All dates and observations were sorted in ascending chronological order (i.e. the oldest in the uppermost row and the most recent at the bottom). Spatial data (using Egyptian Governorate outbreak points with latitudes and longitudes of all locations) were entered and coded in a Geolocation file. Each outbreak point corresponded to a different geographic location matched to a set of temporal parameters. Spatial analysis was conducted using the EPIPOI software. The demarcation between Upper (Southern) and Lower (Northern) Egypt was set at Latitude 30 degrees based on the location of the capitals of each governorate. The monthly geographical distribution of poultry H5N1 outbreaks in Egypt was recorded in 24 governorates from 2006 to 2015.

\section{Spatial phylogenetic analysis}

The geographic locations were selected to represent the positive flocks from the early reported disease outbreaks of each virus cluster on yearly basis from 2006 to 2015 . The genetic data of the full length HA gene were retrieved from the national repository for Egyptian viruses based at NLQP and from Influenza Research Database, which is a public database and analysis resource for influenza sequences. The viruses were analysed in relation to discrete geographic areas, namely Upper Egypt, Lower Egypt and other suitable classifications.

\section{Temporal analysis}

Time-series analyses for annual, bi-annual and quarterly HPAI occurrences and primary peaks across governorates were conducted using the EPIPOI software. The time series analysis of $\mathrm{A} / \mathrm{H} 5 \mathrm{~N} 1$ outbreaks in Egypt from 2006 to 2015 was plotted and the time series analysis model (red line) over the original time series (grey line) was obtained by summing up the 12-month, 6 -month and 3 -month harmonics plus the trend. 


\section{Results}

\section{Spatial and temporal analysis of outbreaks}

HPAI H5N1 outbreaks in Egypt were continuously reported every year since the first reported occurrence of the disease in February 2006 (Figure 1). Out of total 3338 positive samples reported over the 10-year period of this study, 1007 (30\%) samples were confirmed during the early introduction in 2006, and they were mostly from the commercial poultry production sector (Figure 2). The total number of H5N1 outbreaks reported from 2007 onwards represented $70 \%$ of the overall confirmed disease outbreaks in the country to date. Whereas the commercial poultry was the dominant sector affected by the disease outbreaks in 2006, subsequent outbreaks and documented cases from 2007 onward originated mainly from the household poultry production sector (Figure 2).

The H5N1 outbreaks were detected in both Upper and Lower Egypt and covered 96.3\% (26/27) of all governorates in Egypt. The higher numbers of disease outbreaks were reported from Sharkia, Qalyobia, Menufia, Dakahlya and Gharbia governorates in Lower Egypt and from Giza, Fayoum and Menia in Upper Egypt. Many of these Governorates are the leading poultry producing governorates in Egypt (Figure 3) (ElMasry et al., 2015).

The general trend according to the EPIPOI software appeared to support the observation that the number of outbreaks and reported cases in poultry increase during the cooler months of the year (NovemberApril) with peaks in March. If the 2006 data were excluded, the peaks shifted to January (Figure 4, Table 1, Appendix 1). In addition, the broad outline of the time-series confirmed that the peaks of HPAI H5N1 outbreaks occurred from January to March without any marked difference between the governorates in Upper and Lower Egypt (Figure 5, Appendix 1). H5N1 outbreaks were detected randomly in both household and commercial poultry production sectors in Upper and Lower Egypt alike.

The highest incidence was recorded in chicken, which was by far the main gallinaceous poultry species in both commercial farms
(1034/1142; 90.5\%) and household (590/2065; 28.6\%) sectors (Table 2), while duck was the main Anatidae birds with more reports of outbreaks in the households $(361 / 2065 ; 17.5 \%)$ and in LBMs (59/131; 45.0\%). It should be noted that the mixing of different bird species in the household sector remains a major problem by constituting drivers of diseases with more than $52 \%(1076 / 2065)$ incidence rate reported by any sector. The reported numbers of disease outbreaks in other poultry species such as turkey, quail and goose were comparatively low ( $\mathrm{n}=74,3$ and 30 , respectively, for the study period) (Table 2). Commercial chickens accounted for $84.2 \%$ (848/1007) of the total disease outbreaks in 2006 , but $34.2 \%$ (1140/3338) of the overall disease outbreaks from 2006-2015,

Table 1. Number of confirmed $\mathrm{H} 5 \mathrm{~N} 1$ outbreaks in poultry based on monthly timelines in the period 2006-2015.

\begin{tabular}{lcc} 
Month & $\begin{array}{c}\text { Outbreaks including } \\
\text { 2006 data, n (\%) }\end{array}$ & $\begin{array}{c}\text { Outbreaks excluding } \\
\text { 2006 data, n (\%) }\end{array}$ \\
January & $448(13.4)$ & $448(19.2)$ \\
February & $527(15.8)$ & $420(18.0)$ \\
\hline March & $964(28.9)$ & $331(14.2)$ \\
April & $402(12.0)$ & $206(8.8)$ \\
\hline May & $161(4.8)$ & $141(6.0)$ \\
June & $178(5.3)$ & $171(7.3)$ \\
\hline July & $71(2.1)$ & $70(3.0)$ \\
August & $45(1.3)$ & $43(1.8)$ \\
\hline September & $57(1.7)$ & $49(2.1)$ \\
October & $75(2.2)$ & $73(3.1)$ \\
\hline November & $98(2.9)$ & $90(3.9)$ \\
December & $312(9.3)$ & $289(12.4)$ \\
Total & $3338(100)$ & $2331(100)$ \\
\hline
\end{tabular}

The total number of cases per annum 2006-2015 includes the following: 2006 (1007); 2007 (282); 2008 (115); 2009 (176); 2010 (476); 2011 (386); 2012 (97); 2013 (98); 2014 (366) and 2015 (335).

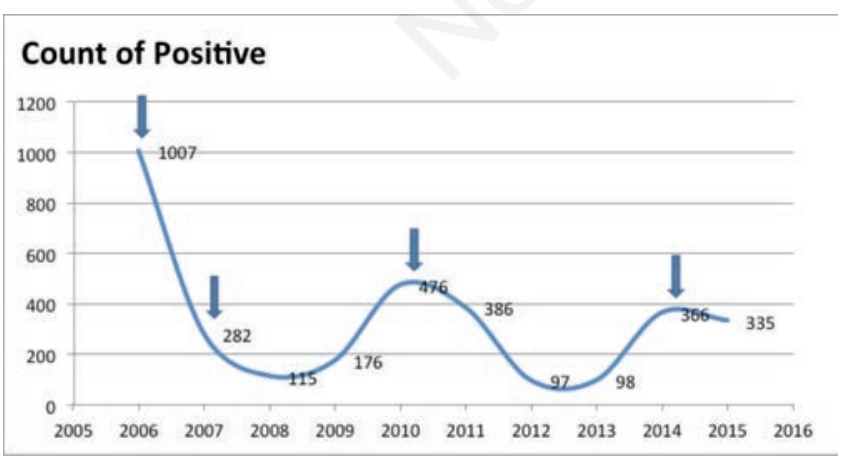

Figure 1. Number of annual highly pathogenic avian influenza A/H5N1 outbreaks recorded in poultry from 2006 to 2015. The arrows refer to the incidence of clear four waves of outbreaks along the whole 9 years of virus persistence. The first wave occurred between February and May 2006, the second from December 2007 to May 2008, the third from November 2010 to April 2011, and the last between October 2014 and February 2015.

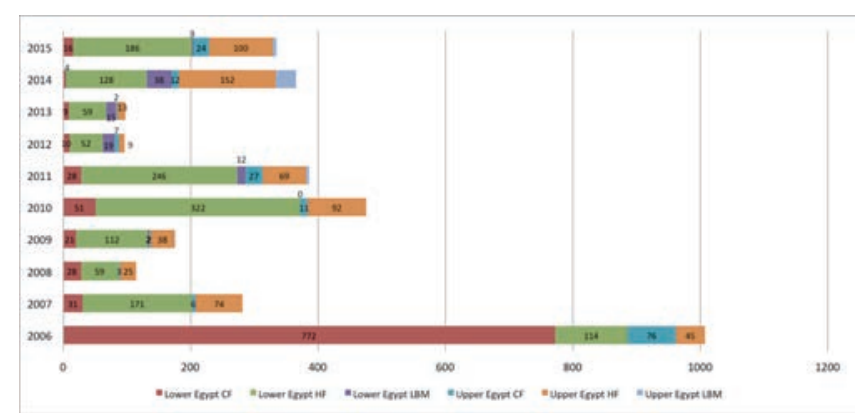

Figure 2. Total number of outbreaks recorded per year from different poultry production sectors. CF, Commercial farms; HF, Household farms; LBM, Live bird markets. Positive samples were obtained from the commercial farms and household poultry in 2006-2008, and from 2009 onwards, also from the LBMs. Lower Egypt included: Alexandria, Behera, Cairo, Dakahlia, Dumyat, Gharbia, Ismailia, Kafr EISheikh, Matrouh, Menofia, North Sinai, Port Said, Qalubiya, Sharkia, South Sinai and Suez; Upper Egypt included: Assiut, Aswan, Beni Suef, Fayoum, Giza, Luxor, Menia, New Valley, Qena and Sohag. 
with sharp decline and shift towards the household poultry between 2007 and 2015 (Figure 2).

\section{Geo-mapping of disease outbreaks and phylogenetic analysis}

The phylogenetic tree of the HA sequences of Egyptian H5N1 viruses showed that multiple phylogenetically distinct clusters co-circulated in Egypt from 2006 to 2015 indicative of persistent virus evolution and predominance of the endemic clade 2.2.1.2 cluster in Egypt. However, viruses from Upper and Lower Egypt never formed a monophyletic group but were interspersed among each other, a signature of concurrent re-infections for the bird populations within the country (Figures 6 and 7).

\section{Discussion}

We have produced evidence of continuous circulation and mapped avian influenza H5N1 in Egypt. It should be stated that the surveillance activities were jointly planned by the Egyptian General Organization of Veterinary Services (GOVS) the National Laboratory for Veterinary Quality Control on Poultry Production (NLQP), Animal Health Research Institute (AHRI) and the Emergency Center of Transboundary Animal Diseases (ECTAD), Food and Agriculture Organization (FA0) of the United Nations. Internal and external quality assurances were ensured during samples collection, transportation, preparation, storage and handling in the field and laboratory to minimise error and validated results were communicated promptly to ensure rapid control by authorities and reduce further transmission within and among flocks. Importantly, we sampled different sectors and various types of birds and these samples were collected over all seasons of the year and all geographical areas in Egypt.

Although most of the countries earlier infected have succeeded in eliminating the HPAI H5N1 virus from their territories after the initial outbreaks between 2003 and 2006, the virus still persists in some South-East Asian countries, including China, Indonesia, Vietnam, Bangladesh as well as Egypt (FA0, 2013). In Egypt, sporadic outbreaks continue to be recorded all year-round in poultry and the virus has been the cause of many human infections and fatalities in different locations. The mechanism of HPAI H5N1 virus spread and persistence and the role of human-animal interactions and human infections is so far only partially explored.

Table 2. Number of confirmed H5N1 outbreaks in different poultry species and sectors in the period 2006-2015.

\begin{tabular}{lcccc} 
Species & Farm (\%) & Household (\%) & LBM (\%) & Total (\%) \\
Chicken & $1034(90.5)$ & $590(28.6)$ & $11(8.4)$ & $1635(49.0)$ \\
Ducks & $52(4.6)$ & $361(17.5)$ & $59(45.0)$ & $472(14.1)$ \\
\hline Geese & $0(0)$ & $21(1.0)$ & $9(6.9)$ & $30(0.9)$ \\
Mixed & $4(0.4)$ & $1076(52.1)$ & $35(26.7)$ & $1115(33.4)$ \\
\hline Other & $4(0.4)$ & $4(0.2)$ & $1(0.8)$ & $9(0.3)$ \\
Quails & $2(0.2)$ & $0(0)$ & $1(0.8)$ & $3(0.1)$ \\
Turkey & $46(4.0)$ & $13(0.6)$ & $15(11.5)$ & $74(2.2)$ \\
Total & $1142(34.2)$ & $2065(61.9)$ & $131(3.9)$ & $3338(100)$ \\
\hline
\end{tabular}

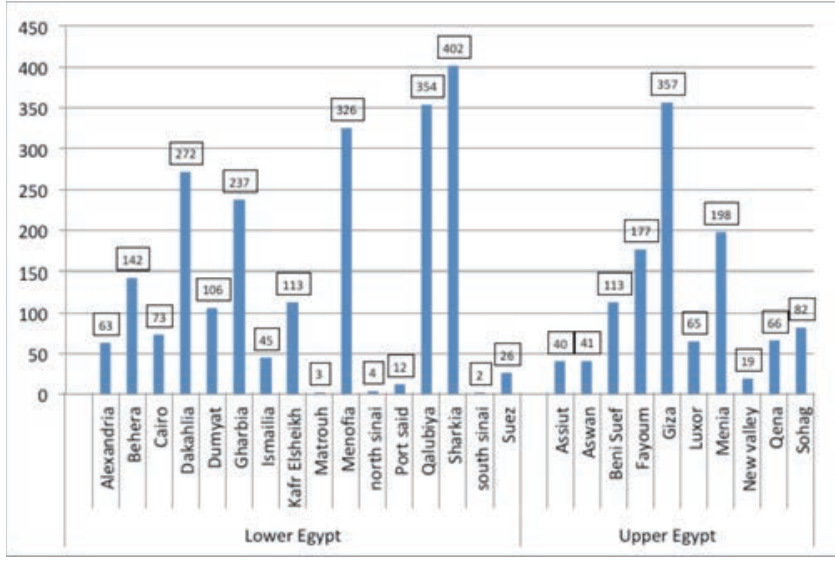

Figure 3. Geographical distribution of recorded highly pathogenic avian influenza $\mathrm{A} / \mathrm{H} 5 \mathrm{~N} 1$ outbreaks in twenty-six Egyptian governorates in the period 2006-2015.

\section{A}

B

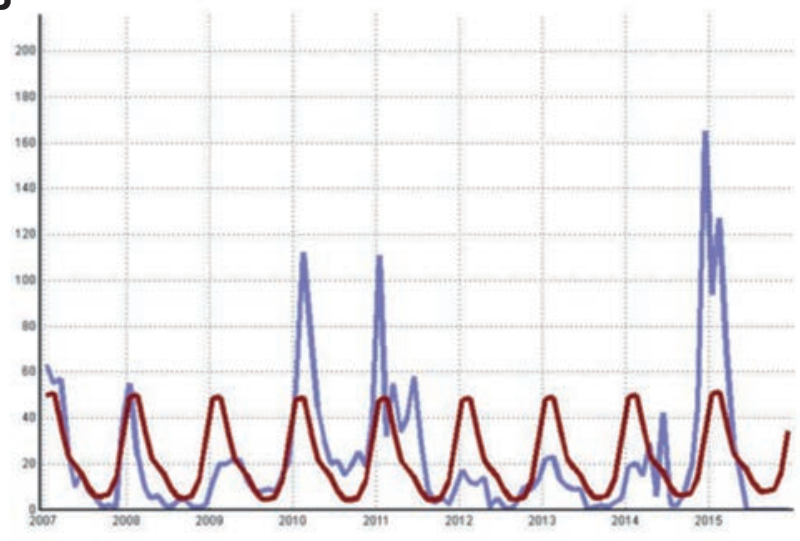

Figure 4. A) Time series analysis of influenza A/H5N1 outbreaks in Egypt from 2006 to 2015; B) partial view of the time series analysis of influenza $\mathrm{A} / \mathrm{H} 5 \mathrm{~N} 1$ outbreaks in Egypt from 2007 to 2015. Purple indicates original time series obtained by summing the 12-monthly, 6-monthly and 3-monthly harmonics, while red indicates time series modeled graph.

LBM, live bird market. 
The lack of detailed epidemiological information and data integrity is another obstacle that hinders the improvement of control strategies. Certain aspects of the temporal and spatial patterns of HPAI outbreaks that occurred in backyard and commercial chicken production systems in Egypt have been described (Abdelwhab and Hafez, 2011; Cattoli et al., 2011). These workers concluded that most of the outbreaks in poultry and humans occurred in the highly populated Nile delta, while the temporal patterns of the virus has changed with outbreaks occurring in the warmer months of the year since 2009. While our conclusion agrees with the former assertion, it differes from the latter as we have now produced evidence of an increased number of outbreaks in the cooler months. However, whether an analysis that excludes the early outbreaks of 2006, a period when epidemiological gathering was still partially unorganised due to lack of previous experience with HPAI H5N1, will produce different conclusion similar to the outcomes of these workers is beyond the scope of our present evaluation.

Previous study (Pavade et al., 2011) have found out that the performance of the country's veterinary services using the OIE PVS evaluation tool (OIE, 2013) have an impact on HPAI control; the higher the performance scores, the less the AI eradication time, mortality rate, culling rate and occurrence of outbreaks. It can be concluded that countries that have better control of HPAI H5N1 are more transparent and provide adequate funding for the development and maintenance of efficiently performing veterinary services (Pavade et al., 2011). Whether Egypt falls fully into this category is, however, doubtful. HPAI H5N1 is now endemic in Egypt and rapid virus elimination in the country may not be easily achieved, at least not in the foreseeable future (FA0, 2011). The virus has been established in poultry in the Nile Delta, where dense human population and poultry stocks are concentrated (El-Zoghby et al., 2013).

In this work, we describe the seasonal pattern of reported H5N1outbreaks and studied the virus-spread characteristics in Egypt. The outbreaks were found to be characterized by seasonal peaks; similar outcomes have been reached by Cattoli et al. (2011), who described three waves between 2006 and 2010. In this study, the positive samples occurred in four waves. The first occurred from February to May 2006 and was characterized by severe destruction of poultry due to the widespread occurrence of the newly introduced $\mathrm{H} 5 \mathrm{~N} 1$ virus, clade 2.2 .1 into the country. The second occurred from December 2007 to May 2008 and was characterized by emergence of a new variant of clade 2.2.1.1 associated with severe destruction of commercial poultry, including vaccinated flocks due to vaccination breaks occurring as a result of marked divergence of the variant viruses of the newly emerged clade 2.2.1.1 from the vaccine seed strains. The third wave occurred from November 2010 to April 2011 and was characterized by the predominance of an endemic emerging clade 2.2.1, afterwards named clade 2.2.1.2. The fourth was recently reported in the winter of 2014/2015 and was characterized by re-emergence of severe epidemics in backyard birds and associated with frequent human infections that were identified as a new cluster of the endemic clade 2.2.1.2 (Figure 1) (Arafa et al., 2015).

The results of epidemiological analysis from disease outbreaks recorded from the period 2006-2015 clearly confirm the endemic nature of $\mathrm{H} 5 \mathrm{~N} 1$ virus infections in the different production sectors in Egypt. The higher frequencies occurred in the cooler months (Figure 4A, Table 1, Appendix 1) perhaps due to the higher demand for poultry breeding flocks to produce meat and eggs to meet the needs during the school season, the harvest season of green feed and during Christmas. It has also been reported that the virus survival time in the cold environment is enhanced (Paek et al., 2010; Kurmi et al., 2013). Previous reports claim that subtype $\mathrm{H} 5 \mathrm{~N} 1$ infections in poultry are associated with poultry densities and has been highly correlated with crop produc- tion (Bodbyl-Roels et al., 2011; Fuller et al., 2013; El-Masry et al., 2015).

Due to increasing human populations and expanding urbanization, mounting demand has been placed on poultry. However, the integrated and highly organized production sectors (1 and 2) in Egypt have insufficient production capacities to meet these demands, and the shortfall

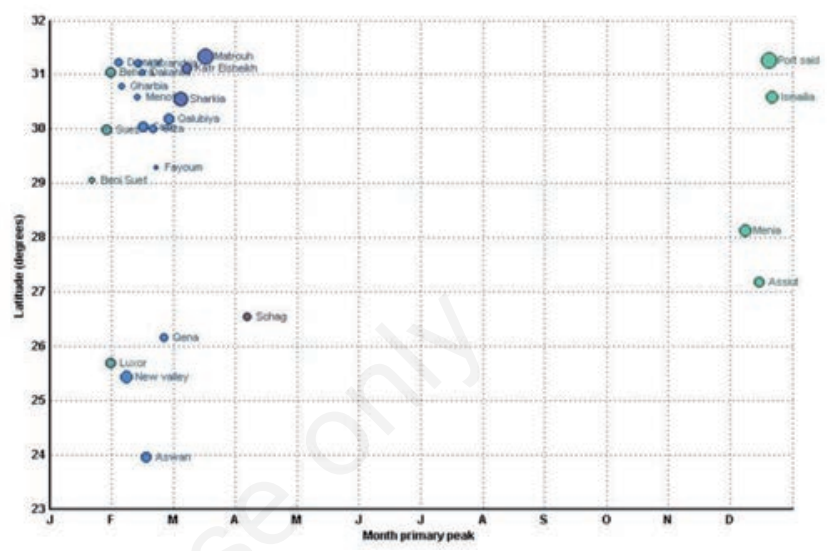

Figure 5. Monthly geographical distribution of recorded influenza $\mathrm{A} / \mathrm{H} 5 \mathrm{N1}$ outbreaks in poultry in Egypt in twenty-four governorates (plots) from 2006 to 2015 in relation to latitudes (23$32^{\circ}$ ) using EPIPOI software. Comparing the seasonality of time series geographically, the graph shows a latitudinal gradient in the timing of peak H5N1 influenza outbreaks in Egypt. The size of marker points corresponds to the amplitude of $\mathrm{A} / \mathrm{H} 5 \mathrm{~N} 1$ avian influenza seasonality over years and the sizes are proportional to the amplitudes, and the different colours denote the differences in peak timing of each Egyptian governorate.

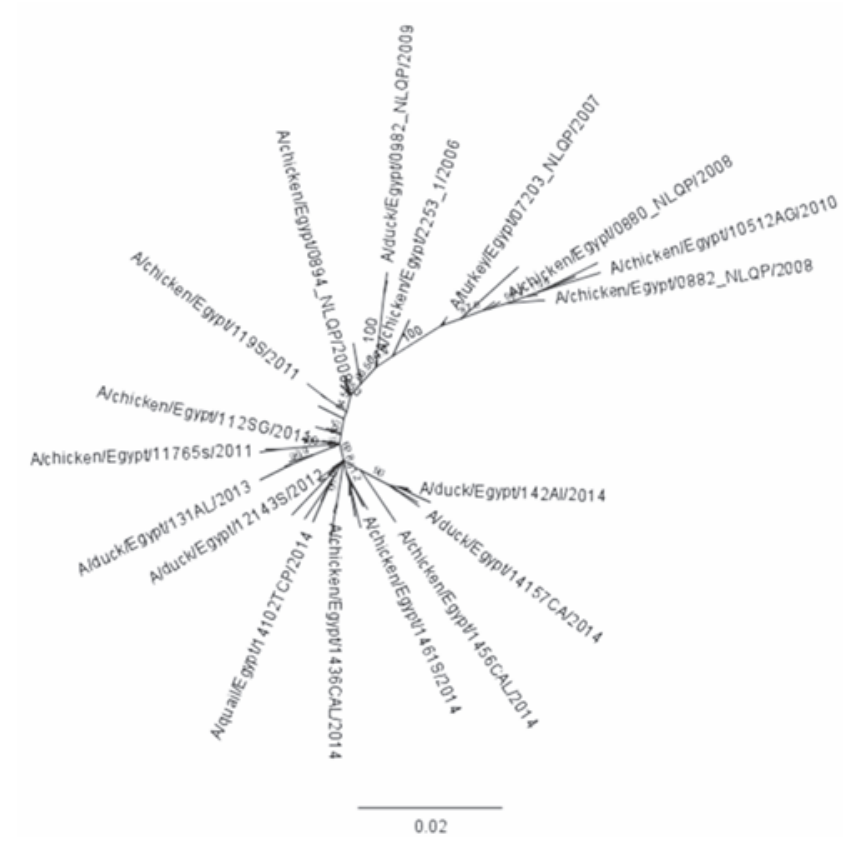

Figure 6. Phylogenetic tree of haemagglutinin gene sequences of Egyptian $\mathrm{H} 5 \mathrm{~N} 1$ viruses showing multiple distinct clade 2.2.1.clusters circulating from 2006 to 2015 . The selected virus reflects the earliest reported outbreaks for each cluster every year. 
has been met to date by the unorganized, unregistered and intricately concentrated small-scale poultry producers. These small-scale producers constitute the majority of sector 3 of broilers and layers, and possibly part of sector 4 , and they are considered a high risk for poultry disease occurrence and transmission because they are constantly exposed to poultry pathogens due to low levels of compliance with instituted biosecurity measures (Sheta et al., 2014).

After the first introduction of the virus in Egypt in 2006, a huge number of disease outbreaks were reported in commercial farms $(n=848)$ and by March 2006, the reported highest number of disease notification rate per month has been obtained for the whole period of evaluation until 2016 (Figure 4A, Table 1, Appendix 1). This observation may have been due to a combination of factors including the application of ineffective compensation policy by the government in the early phase of outbreaks facilitating easy spread of the virus. It is also plausible that in the event of a report of an emerging disease, particularly when occurring for the first time, an unprepared veterinary service would not be able to implement immediate control, thus the risk of transmission increases. Based on these reasons, the records of 2006 were removed to eliminate analytic bias and a rerun of the analysis returned cumulative monthly peaks, which annually shifted from March to January (Figure 4B).

Our results revealed no specific spatial pattern of distribution of H5N1 in Egypt, an indication that the virus circulated wherever the poultry was present. However, a relatively higher number of disease outbreaks was recorded in poultry flocks in the Delta of Lower Egypt (El-Zoghby et al., 2013), but there is also a higher proportion of poultry in this region. However, certain governorates including Matrouh, South Sinai, North Sinai, Port Said and New Valley reported very few disease outbreaks and no report came from the Red Sea governorate (Figure 3) probably due to the lowest number of human population and poultry density in these areas as well as low volumes of poultry trades. Because poultry is also moved within the governorates for trade and other purposes, the discrepancy in the number of disease outbreaks among governorates may not reflect the true distribution of the disease per governorate. In addition, due to the variations in the degree of transparency for disease reporting and the level of implemented surveillance systems among governorates, this type of variation may exist.

To date, Egypt remains one of the few countries with intense and persistent infection by H5N1 in poultry flocks with infection and reinfection of human populations. Previous workers have suggested that recurrent human infections may be occurring primarily through droplet transmission arising from close contact with infected poultry (Murray and Morse, 2011). We identified four waves in poultry with incidence of human infections. In Egypt, the highest incidence remains in the Nile Delta region where high densities of poultry populations and activities have been established alongside dense human populations. The unorganized marketing networks and poultry's spatial distributions within the human household are possible risk factors for human infections.

Although a disproportionately higher frequency of disease outbreaks were reported in the household poultry sector, especially in chicken and ducks in the Nile Delta from 2007, the results can only partially reflect the true situation because of the prevailing under-reporting in the commercial sector and the surveillance activities' biases towards the household sector; however it may also be a reflection of a widespread endemic situation (Kayali et al., 2011).

Generally, commercial farms underreport to protect their business interests and prevent mass culling of their stocks (FAO, 2011). In addition, the observed increases in reported cases in the household poultry during 2010/2011 may also reflect increases in the surveillance activi- ties rather than changes in the virus dynamics during that period. The utilisation of rapid antigen detection test nationwide at the public veterinary clinics and the implementation of participatory disease search (community-based animal health and outreach programme-CAHO) enhanced the surveillance programmes. The clade 2.2.1.2 H5N1 viruses have become established in poultry in Egypt, accounting for a majority of documented human infections in recent years (WHO/OIE/FAO, 2012; Arafa et al., 2016).

Progressive evolution of the H5N1 virus may have occurred in some governorates where multiple genotypes of viruses have circulated in different years; for example, the New Valley governorate recorded a total of 19 cases of $\mathrm{H} 5 \mathrm{~N} 1$ in two separate occurrences, one during 2010 , and the other one during an outbreak from February to March 2013 and the isolated virus had the features of the clade 2.2.1.2 virus that predominated in the 2013 outbreaks. Similarly, the isolates from Assiut during the 2012 and 2014 outbreaks were part of the evolving clade 2.2.1.2 cluster that carries the same genetic relatedness and that may indicate minimal inter-governorates introduction of the virus. However the small number of positive samples from these governorates does not provide strong evidence to support such homogeneity, especially when a governorate like Assiut is located between the moderate to high-risk infections areas of Menia, Sohag, Qena and Luxor (Figure 7).

The fact that outbreaks continue to be reported despite the widely practised vaccination against HPAI H5N1 virus cast doubt on the effectiveness of the practise in Egypt Inadequate vaccination coverage, suboptimal dosage and improper application may have contributed to the observed vaccination ineffectiveness. In addition, despite the widespread and indiscriminate use of vaccines, monitoring is hardly conducted. Strategically, quality-assured vaccines should be selected and used in high-risk areas against circulating strains and with consideration for the ease of applications. Other workers have suggested that improper vaccinations and poor quality vaccines have led to disease outbreaks (Peyre et al., 2009; FA0, 2011).

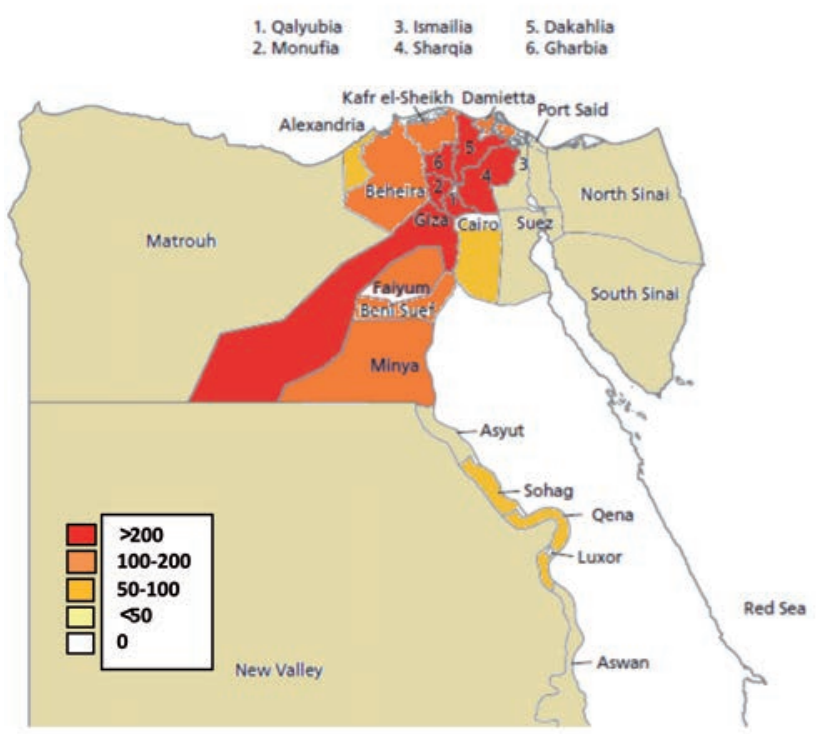

Figrue 7. Map of Egypt showing the distribution of numbers of positive samples among governorates. 


\section{Conclusions}

We have described HPAI H5N1 virus outbreaks in Egypt in spatial and temporal dimensions highlighting the multiple, yet complex factors that may have served as drivers of virus introduction and transmission in poultry and humans. Continuous monitoring of the biological and spatio-temporal characteristics of the circulating viruses becomes necessary, and application of good farming and biosecurity principles as well as vaccine studies are all needed to combat the continued spread of the virus in Egypt.

\section{References}

Abdel-Moneim AS, Shany SA, Fereidouni SR, Eid BT, El-Kady MF, Starick E, Harder T, Keil GM, 2009. Sequence diversity of the haemagglutinin open reading frame of recent highly pathogenic avian influenza H5N1 isolates from Egypt. Arch Virol 154:1559-62.

Abdelwhab E, Hafez H, 2011. An overview of the epidemic of highly pathogenic H5N1 avian influenza virus in Egypt: epidemiology and control challenges. Epidemiol Infect 139:647-57.

Alonso WJ, McCormick BJ, 2012. EPIPOI: a user-friendly analytical tool for the extraction and visualization of temporal parameters from epidemiological time series. BMC Public Health 12:982.

Arafa A, El-Masry I, Kholosy S, Hassan MK, Dauphin G, Lubroth J, Makonnen YJ, 2016. Phylodynamics of avian influenza clade 2.2.1 H5N1 viruses in Egypt. Virol J 13:49.

Arafa A, Naguib M, Luttermann C, Selim A, Kilany W, Hagag N, Samy A, Abdelhalim A, Hassan M, Abdelwhab E, 2015. Emergence of a novel cluster of influenza A (H5N1) virus clade 2.2. 1.2 with putative human health impact in Egypt, 2014/15. Euro Surveill 20:2-8.

Bodbyl-Roels S, Peterson AT, Xiao X, 2011. Comparative analysis of remotely-sensed data products via ecological niche modeling of avian influenza case occurrences in Middle Eastern poultry. Int J Health Geogr 10:1.

Cattoli G, Milani A, Temperton N, Zecchin B, Buratin A, Molesti E, Aly MM, Arafa A, Capua I, 2011. Antigenic drift in $\mathrm{H} 5 \mathrm{~N} 1$ avian influenza virus in poultry is driven by mutations in major antigenic sites of the hemagglutinin molecule analogous to those for human influenza virus. J Virol 85:8718-24.

El-Masry I, Elshiekh H, Abdlenabi A, Saad A, Arafa A, Fasina F, Lubroth J, Jobre Y, 2015. Avian influenza H5N1 surveillance and its dynamics in poultry in live bird markets, Egypt. Transbound Emerg Dis doi:10.1111/tbed.12440.

El-Zoghby E, Aly M, Nasef S, Hassan M, Arafa A, Selim A, Kholousy A, Kilany W, Safwat M, Abdelwhab E, Hafez H, 2013. Surveillance on A/H5N1 virus in domestic poultry and wild birds in Egypt. Virology J 10:203.

Fasina F, Ali A, Yilma J, Thieme 0, Ankers P, 2016. Production parameters and profitability of the Egyptian household poultry sector: a survey. World Poultry Sci J 72:178-88.

FAO, 2011. Approaches to controlling, preventing and eliminating H5N1 highly pathogenic avian influenza in endemic countries. Food and Agriculture Organization, Rome, Italy. Available from: http:/www.fao.org/docrep/014/i2150e/i2150e00.htm

FA0, 2013. Mapping influenza A (H5N1) virus transmission pathways and critical control points in Egypt. Food and Agriculture Organization, Rome, Italy. Available from: http//www.fao.org/docrep/017/i3272e/ i3272e.pdf

Fuller TL, Gilbert M, Martin V, Cappelle J, Hosseini P, Njabo KY, Aziz SA, Xiao $\mathrm{X}$, Daszak P, 2013. Predicting hotspots for influenza virus reassortment.
Emerg Infect Dis 19:581-8.

Jones B, 2008. Introduction of participatory epidemiology to strengthen animal disease surveillance and control: an assessment report for FAO, ECTAD-Egypt, 2008. International Livestock Research Institute, Nairobi, Kenya.

Kayali G, Webby RJ, Ducatez MF, El Shesheny RA, Kandeil AM, Govorkova EA, Mostafa A, Ali MA, 2011. The epidemiological and molecular aspects of influenza H5N1 viruses at the human-animal interface in Egypt. PLoS One 6:e17730.

Kurmi B, Murugkar HV, Nagarajan S, Tosh C, Dubey SC, Kumar M, 2013. Survivability of highly pathogenic avian influenza $\mathrm{H} 5 \mathrm{~N} 1$ virus in poultry faeces at different temperatures. Indian J Virol 24:272-7.

Murray EJ, Morse SS, 2011. Seasonal oscillation of human infection with influenza A/H5N1 in Egypt and Indonesia. PloS One 6:e24042.

OIE, 2013. OIE tool for the evaluation of performance of veterinary services. $6^{\text {th }}$ ed. World Organisation for Animal Health, Paris, France. Available from: http:/www.oie.int/fileadmin/Home/eng/Support_to_OIE_ Members/pdf/PVS_A_Tool_Final_Edition_2013.pdf

Paek MR, Lee YJ, Yoon H, Kang HM, Kim MC, Choi JG, Jeong OM, Kwon JS, Moon OK, Lee SJ, Kwon JH, 2010. Survival rate of H5N1 highly pathogenic avian influenza viruses at different temperature. Poultry Sci 89:1647-50.

Pavade G, Awada L, Hamilton K, Swayne DE, 2011. The influence of economic indicators, poultry density and the performance of veterinary services on the control of high-pathogenicity avian influenza in poultry. Rev Sci Tech OIE 30:661-71.

Peyre M, Samaha H, Makonnen YJ, Saad A, Abd-Elnabi A, Galal S, Ettel T, Dauphin G, Lubroth J, Roger F, Domenech J, 2009. Avian influenza vaccination in Egypt: limitations of the current strategy. J Mol Genet Med 3:198-204.

Sheta BM, Fuller TL, Larison B, Njabo KY, Ahmed AS, Harrigan R, Chasar A, Aziz SA, Khidr AA, Elbokl MM, 2014. Putative human and avian risk factors for avian influenza virus infections in backyard poultry in Egypt. Vet Microbiol 168:208-13.

Slomka M, Pavlidis T, Banks J, Shell W, McNally A, Essen S, Brown I, 2007. Validated H5 Eurasian real-time reverse transcriptase-polymerase chain reaction and its application in H5N1 outbreaks in 2005-2006. Avian Dis 51:373-7.

Spackman E, Senne DA, Myers TJ, Bulaga LL, Garber LP, Perdue ML, Lohman K, Daum LT, Suarez DL, 2002. Development of a real-time reverse transcriptase PCR assay for type A influenza virus and the avian H5 and H7 hemagglutinin subtypes. J Clin Microbiol 40:3256-60.

Upton M, 2007. Scale and structures of the poultry sector and factors inducing change: inter-country differences and expected trends. In: Poultry in the 21st Century. Proceedings of the International Conference on Avian Influenza and Beyond. Bangkok 5-7 November 2007. Available from: http:/www.fao.org/ag/againfo/home/events/bangkok2007/en/index.html

WHO, 2016. Cumulative number of confirmed human cases for avian influenza A(H5N1) reported to WHO, 2003-2016. World Health Organization, Geneva, Switzerland. Available from: http:/www.who.int/influenza/human_animal_interface/2016_07_19_ta bleH5N1.pdf?ua=1

WHO-EMRO, 2015. Egypt: upsurge in H5N1 human and poultry cases but no change in transmission pattern of infection, 2015. World Health Organization Regional Office for Eastern Mediterranean, Cairo, Egypt. Available from: http//www.emro.who.int/egy/egypt-news/upsurge-h5n1human-poultry-cases-may-2015.html

WHO/OIE/FAO, 2012. Continued evolution of highly pathogenic avian influenza A (H5N1): updated nomenclature. Influenza Other Respir Viruses 6:1-5. 